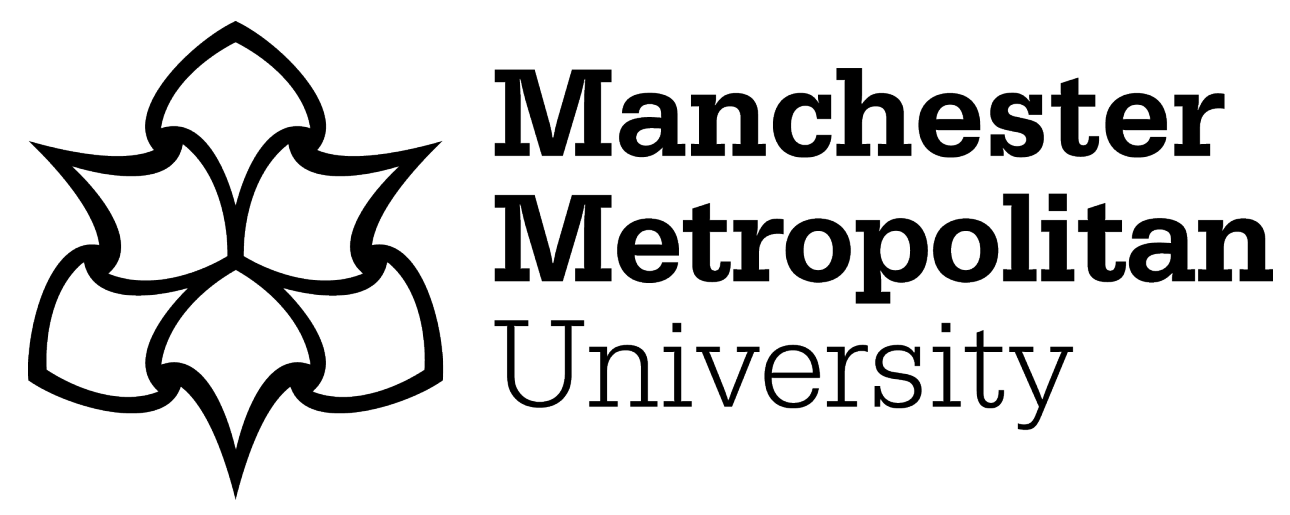

Needham, MD, Kuleimenov, D and Soltanbekova, A (2018) Sticking and tipping points: a case study of preschool education policy and practice in Astana, Kazakhstan. European Early Childhood Education Research Journal, 26 (3). pp. 432-445. ISSN 1350-293X

Downloaded from: https://e-space.mmu.ac.uk/620576/

Publisher: Taylor \& Francis (Routledge)

DOI: https://doi.org/10.1080/1350293X.2018.1463909

Please cite the published version 


\title{
Sticking and tipping points: a case study of preschool education policy and practice in Astana, Kazakhstan.
}

\author{
Martin Needham*, Daurenbek Kuleimenov**, Arailym Soltanbekova** \\ *Education and Social Research Institute, Manchester Metropolitan University \\ ** Nazarbayev Intellectual Schools, Nazarbayev University
}

\begin{abstract}
This article presents a case study exploring how national guidance for kindergartens in Kazakhstan were interpreted in practice. Document analysis of the State Education Standards of Preschool Upbringing and Education, together with stakeholder interviews and observations of six Astana kindergarten settings illustrate how competing perspectives on preparing children for school can both promote and limit opportunities for child-led activity in early education. The article considers post-colonial and neo-colonial pasts and their potential to influence the present, identifying potential sticking points that may limit change processes. The article suggests processes for building locally grounded praxis in order to create tipping points where childinitiated pedagogy could become a more frequent feature of practice.
\end{abstract}

\section{Keywords}

Kindergarten Standards, Neo-colonial, Kazakhstan, Modernity, Change, Quality

\section{Introduction}

This article examines the challenges of developing fluidity and cohesion in practice associated with a policy intended to change early years practice in Kazakhstan. It explores the influence of 'traditional' colonial and 'modernising' neo-colonial pasts (Braidotti 2013) on present kindergarten practices in Astana, the capital of Kazakhstan. Policy change is notoriously complex to effect; Ball and Junemann (2012: 87) explore the significance and nature of the 
influence exerted by "boundary-spanners" agents who act to span "structural holes" in network systems. In this article Gladwell's analysis of the factors that generate a 'tipping point' as "the moment of critical mass, the threshold, the boiling point" (2000: 12) is used to reflect on the importance of including localised processes in response to the advancement of national and international standards of quality in early educational practice. A review of Kazakhstan's National Standards for Kindergarten Education and Upbringing (2012), a document intended to support change in preschool practice in Kazakhstan, forms the basis of a case study that illustrates the tensions policy makers and practitioners can experience between neo-colonial, internationally recommended directions of change and the persistence of past-colonial pedagogical cultures. In this case study, pedagogical ideas shaped in a Soviet colonial past seem to resist more play-based kindergarten practices developed in other cultural contexts. The Head of preschool programmes, in the Ministry of Education summarised the Kazakh government's agenda: "The priority for change is to move from a more school-like classroom environment to a more play based experience for children". A kindergarten practitioner characterised her revised practice as involving less "teaching from the front". This article explores the nature, relevance, and ethics of pedagogical change.

\section{The context of Kazakhstan and Astana}

Kazakhstan is the world's ninth largest nation by geographical area; however, with around 17 million people, it is one of the least densely populated (Bridges and Sagintayeva 2014). Kazakhstan gained independence from the former Union of Soviet Socialist Republics in 1991 and the two leading languages are Russian and Kazakh. The initial challenges of developing social infrastructure together with establishing new economic and political institutions continue to be tackled, with a growing sense of national identity and increasing affluence from the cultural and mineral wealth of the nation (Aitken 2012, Bridges and Sagintayeva 2014).

Astana, the modern capital of Kazakhstan, has a dramatic centre comprising contemporary glass and steel buildings fusing architectural styles reflecting its location at the geographical centre of a country that is at the crossroads of Europe and Central Asia. 
Kazakhstan's capital it is becoming a well recognised conference centre for global dialogues between East and West, Europe and Asia, North and South, Islam and other world religions. (Aitken 2012, 186).

The modern city centre sits alongside a previous one with a more 'Soviet era' identity (Brummell 2011) surrounded by more suburban areas. The appearance of the people also conveys the diversity of the vast central Asian region; Kazakhstan comprising 138 national and ethnic groups (Aitken 2012). The interiors design of the buildings present a similar fusion of European and Central Asian forms with references to a more nomadic identity represented in textiles and art. In the capital of this Islamic State, religious identity is not immediately visible: mosques are not obvious or audible, many men and women may dress in 'westernised clothing' and are not segregated in public spaces. Music, film, entertainments, shopping malls, public swimming areas and pleasure parks are features of Astana (Brummell 2011). These observations are included to illustrate the cultural fusions influencing the pastpresent (King 2011) of a new national identity.

\section{An overview of the context kindergarten preschool provision in Kazakhstan.}

In a 2014 interview, a former national Education Advisor described the former Soviet system where kindergartens were widespread, perceived to be of high quality and free to families. Following independence, there was a reduction in the availability of places and a perceived decline in the quality of provision (Aitken 2012). With increasing economic confidence there is now a growing demand for preschool places particularly in the cities, where both parents are more likely to be in employment, and where families are eager for their children to be ready for school. Long waiting lists for kindergarten places means that parents put their children's names forward long before the children are ready to start and some may pay to have their child moved up the waiting list. Grandparents and extended families are significant in caring for children, particularly in rural areas where parents have migrated into the city areas (Education Advisor 2014).

Under the Balpan (Little Chicks) initiative, provision expanded in partnership with private sector investment and the number of children attending preschool had increased from $40 \%$ in 2010 to $75 \%$ in 2013 (Bridges and Sagintayeva 2014) with the intention of offering a kindergarten place for all children aged three to six by 2020 . There is a strong sense of kindergarten as a way of 
preparing children for school. This is manifest in increasing pressure to bring testing into place to assess children in preparation for starting school grades. The Kazakhstan National Preschool Standards (Ministry of Education 2002, 2008, 2012) maintain clear curriculum guidelines for each subject but also include directives to promote more child-centred pedagogies. This tension between a wider societal expectation that preschool will prepare children for school and maintaining a space for children's play in preschool, is experienced in many countries (Moss et al. 2016).

\section{An international preschool movement in favour of increased opportunities for child-led learning.}

In an increasingly interconnected world, the Organisation for Economic Cooperation and Development (OECD) is a powerful monitoring and lobbying group that is supported by 35 member countries. The OECD has done much to promote the expansion of early years services internationally over the last 20 years within and beyond its 35 core members (Yoshikawa 2016) including cooperation with partner countries such as Kazakhstan (OECD 2011). Central to the OECD policy approach is the use of research evidence that constructs high quality provision in relation to individual academic achievement and national economic development. The 'Starting Strong' series of reviews of international early years practice and research evidence (OECD 2012, 2015) has been particularly influential on governmental policies and practices for early years services (Yoshikawa 2016).

Starting Strong III offered a detailed review of the directions of travel for preschool development from case studies across 10 economically different countries (Taguma, Litjens and Makowiecki 2012). Starting Strong III argued that "children are more competent and creative across a range of cognitive areas when they are given the choice to engage in different well-organised and ageappropriate activities." (Taguma, Litjens and Makowiecki 2012:17). The core evidence used in the Starting Strong documents is drawn from longitudinal studies conducted in a number of different countries. Studies fromthe USA, (Schweinhart et al. 2005), New Zealand (Wylie and Thompson 2003) and the UK (Sylva et al. 2010) are brought together in the Starting Strong reports (OECD 2015, 2012) to advocate that allowing children greater control of some of their preschool activities promotes personal responsibility and self-control. This evidence base 
suggests that positive social and intellectual benefits accrue in the primary education phase for children from preschool programmes that balance adult-led and child-led activities. The Starting Strong toolbox (OECD 2012) also identified skills and staff traits associated with facilitating high-quality services and outcomes;

- Good understanding of child development and learning;

- Ability to develop children's perspectives;

- Ability to praise, comfort, question and be responsive to children;

- Leadership skills, problem solving and development of targeted lesson plans; and

- Good vocabulary and ability to elicit children's ideas.

(Taguma, Litjens and Makowieck 2012, 9)

\section{Postcolonial perspectives}

The adoption of international policy recommendations for preschool quality does not go unquestioned (Moss et al. 2016). Sahlberg (2015) expresses concerns that the evidence selected by policy makers to argue for change, relies too heavily on what may be measured, tested and compared in an international context. Such measures may lose sight of children's individual as well as human needs and understandings. Referring to 'cargo cults' Johnson (2000) was deeply critical of the importation of pedagogies divorced from the cultural understandings and experiences that had created them. Similarly postcolonial thinkers draw attention to the way that earlier Nineteenth and Twentieth century national colonializations aspired to bring European enlightenment to the world and continue to shape aspects of international development movements (Janz 2012, Braidotti 2013, Pacini- Ketchabaw and Taylor 2015). They emphasise the importance of considering people rather than homogenising countries as abstracted places that are then described by numerical data sets. They also emphasise the power of underlying assumptions of shared human aspiration and scientific justification that channel developments in particular directions. The idea of pastpresents (King 2011) considers how present enactments draw from shared expectations of past performances. Local heritage and environment may lend greater authenticity (Somdahl-Sands and Finn 2015) to particular types of classroom performance because they resonate with past values. Pacini- Ketchabaw and Taylor (2015) argue in favour of local cultures being closely involved in embedding values into the curriculum. In their review of educational systems in Kazakhstan, Bridges, Kurakbayev, and Kambatyrov 
(2014) suggest that issues of relevance and timing should be explored through a sensitive and respectful cultural dialogue with practitioners. It is only through dialogic research about the reform of professional practice and cultural values, that policy messages can be refined in terms of both content and delivery (McLaughlin, McLellan, Fordham, Chander-Grevatt and Daubney 2014).

This article explores why child-led learning pedagogy, as advocated in the Starting Strong series, might find it difficult to 'stick' in contexts where it is in competition with established models of adult-directed learning. Astana provides an interesting case study of the widespread pressures to control young children's learning (Moss et al. 2016), illuminating ways in which underlying modernising values associated with educational heritage might resist the idea of play as pedagogy.

\section{The trickiness of modernising ideas}

Modern, progressive and traditional are labels that are often used to position newer practice as a superior replacement for established practices in education; however the early Twentieth century colonial templates for school education systems were quintessentially modernising structures. Giddens (1990) sought to break down the idea that there is direct linear progression from modernist organising principles towards post-modern accommodations of individuals' agency in social structures. He pointed out that while individual experiences may be unique, they are still engaging with ideas, processes and structures that are profoundly shaped by the values of modernity embedded in society. Giddens (1990) identifies time-space distanciation as a key feature of modernity. This is the separation of more generalisable knowledge from localised physical experience and this is apparent in the school -based education systems founded in the late Nineteenth and early Twentieth Century that sought to prepare children to be functional in the institutions of contemporary society. A key perceived benefit of a 'modern education' was that the abstracted generalisable knowledge that it promoted enabled school graduates to be able to transfer and apply knowledge to different and changing contexts. Therefore, embedded in the values of many educational contexts is the concept of directing children's learning towards generalizable knowledge and paying less attention to local personal knowledge. 
In addition to the hidden heritage of modernising concepts in education systems, postcolonial scholars also argue for a cautious approach to transferring practices across cultures. They suggest that pedagogic systems need to be understood in order to fit meaningfully within a local systems and structures that will inevitably be influenced by place (Pacini- Ketchabaw and Taylor 2105).

In the days of colonisation, discourses of racial hierarchy were specifically used to justify the acts of indigenous dispossession and white settlement as an inevitable and natural (social evolutionary) process. The assumed "natural" superiority of the civilised and civilising white colonisers was dependent upon the stated "primitiveness" and "backwardness" of the colonised indigenous people. (Pacini-Ketchabaw and Taylor 2015, 12)

Such experiences are a part of the cultural heritage in Kazakhstan where more localised nations and cultures were assimilated through colonial institutions (Aitken, 2011). Braidotti (2013), reviewing post-humanist perspectives, identifies concerns that although racial and cultural superiority is no longer promoted, social systems continue to be fundamentally biased towards adopting European enlightenment measures of success. She argues for new more locally grounded or at least more dialogic exchanges of ideas in order to realise meaningful equitable and sustainable development (Braidotti 2013). Modern economic institutions, such as the OECD, are committed to the belief that children need to be prepared for the codes and practices of the 'western' 'modernising' process of education (Braidotti 2013). Promoting play based, child centred methods may not resonate with the modernising vision of many policy makers because it competes with underlying expectations that children need to be prepared for schools. This discussion is introduced to help explain how early educational institutions seeking to provide individualised play-based experiences may still be drawn to practices that focus on an underlying modernist discourse of preparing children for school. The case study that follows seeks to expose and unsettle the othering binary of traditional and progressive methods in order to create a space where new practices are more likely to evolve.

\section{The stickiness of ideas.}

The tensions between global economic forces and national politics and culture is highlighted by Ball, Goodson and Maguire (2007). As in Ball (1990) attention is drawn to layers in the cycle of 
policy implementation; politicians; bureaucrats and professionals, they point to the mismatch between national policy that is in discourse with the international arena and the realisation of policy through local politics and cultural practices. Tharp and Gallimore (1988) exemplify and discuss this phenomenon through the context of the failure of particular curricular changes to influence practice in the USA because of what they identified as a strong-shared cultural construction of what 'school' is as well as the roles and rules for those involved in educational exchange. They argued that only through a process of consistent challenge of the conceptions of traditional interactive processes will change come about. Ball and Junemann (2012) illustrate the importance of organisations and individuals acting as connectors across institutions in implementing policy change.

Malcom Gladwell's analysis of tipping points is used here as a way to explore the threshold of stickiness/fluidity where colonial and neo-colonial pasts need to be acknowledged as part of a process for developing locally relevant practices in the present. Gladwell (2001) points out that in many fields of social activity it often takes several attempts to get a message into a form that flies and therefore there is an important role for participant engagement, surveys and research dialogues to monitor the development and adoption of ideas. Gladwell (2001) offers many examples of how some ideas stick in the mind relative to others by virtue of relatively small changes in the way they are presented. Key elements of successful ideas are demonstrated messages that fit into a clear narrative, messages that are relevant and accessible to the audience, and messages with which the audience can identify and engage.

Gladwell (2001) identified three factors that help social phenomena reach a tipping point of popular take-up:

1. The stickiness, appeal or power of the idea itself: Gladwell (2001) suggests that what helps ideas stick in people's minds is where they are in small transparently meaningful units, which are free of confusion and a presented in such a way that help people to act upon the information offered.

2. The number, power and connectedness of the key individuals spreading an idea. Gladwell's (2001) analysis of the social transmission of ideas is helpful in reminding us that while a small number of authoritative and influential people can be very effective in transmitting ideas, there 
needs to be a number of smaller working communities or cells into which ideas can be transmitted in order to take root.

3. The circumstances of the context in which the idea is operating. Gladwell's examples are helpful because they illustrate that in many cases it takes time and tinkering with these elements to get the ideas to take off. It is important to understand that context, the material resources and environmental tipping points are things that can be changed. In the context of early years education the signals presented by structures and relationships in preschool environments to children, parents and practitioners can be amended to make ideas more accessible.

These categories are elaborated upon and used to structure the findings that follow.

\section{Methods}

The following case study comprises document analyses of Kazakhstan's 2001, 2008 and 2012 "State Education Standards of Preschool Upbringing and Education", together with kindergarten observations and stakeholder interviews considering progression towards these standards. A qualitative contents analysis (Elo, Kääriäinen, Kanste, Pölkki, Utriainen, and Kyngäs 2014; Robson and McCartan 2016) of the standards documents, initially mapped aspects of policy deductively against categories identified in Starting Strong documents relating to quality enhancements. These elements were then used to inform interview protocols and analysis including further inductive document review against emergingthemes of continuity, change and challenge to pedagogical practices. This dialectic between documents, observations and interview data facilitated insights into the relevance and interpretation of policy in context (Elo et al. 2014). An outline schedule of questions focusing on exploring how the national standards were influencing practice and training was agreed by the research team. Eleven semi-structured interviews were conducted in the preferred language of the interviewees, either Russian or Kazakh. Questions and answers were translated by the two researchers from Nazarbayev University directly in the sessions to support the researcher from Manchester Metropolitan University. Each researcher took notes during the interviews, which were then drawn together in post interview meetings soon after the interviews took place in order to develop a consolidated record of the interviews and identify topics to follow up in subsequent interviews. This 
methodology developed to respect the rights of two of the initial interviewees who declined to be audio recorded (Hamilton \& Corbett-Whittier 2012).

Semi-structured interviews were conducted with two Ministry of Education policy makers and two training leaders with a responsibility for coordinating initiatives at a national and local region level. Interviews were also held with three headteachers from Astana kindergartens. Semi-structured interviews were also conducted with the directors and staff as part of visits to six kindergartens. These were in different areas of the city of Astana and reflected a range of approaches to teaching and learning. Three state kindergartens were visited as recommended by the Republican Centre for Preschools as positive and varied kindergarten environments. Three private settings were also visited as recommended by the Astana city Kindergarten directorate as positive and varied examples kindergartens; one in a privately owned building, two operating in rented accommodation. All the participants were contacted in advance of the visits by Nazarbayev university to explain the nature of the visits, rather than by government officials. Participants' anonymity and the right to withdraw or not answer questions were reasserted at the beginning of each interview.

Table 1 A Summary of Interviews

Minister for Education (A)

National Director for Early Education (B) $\quad$ National Director for in-service training (C)

Former national education policy advisor (D)

An Astana District training officer together with 3 Kindergarten Headteachers/Trainers (E)

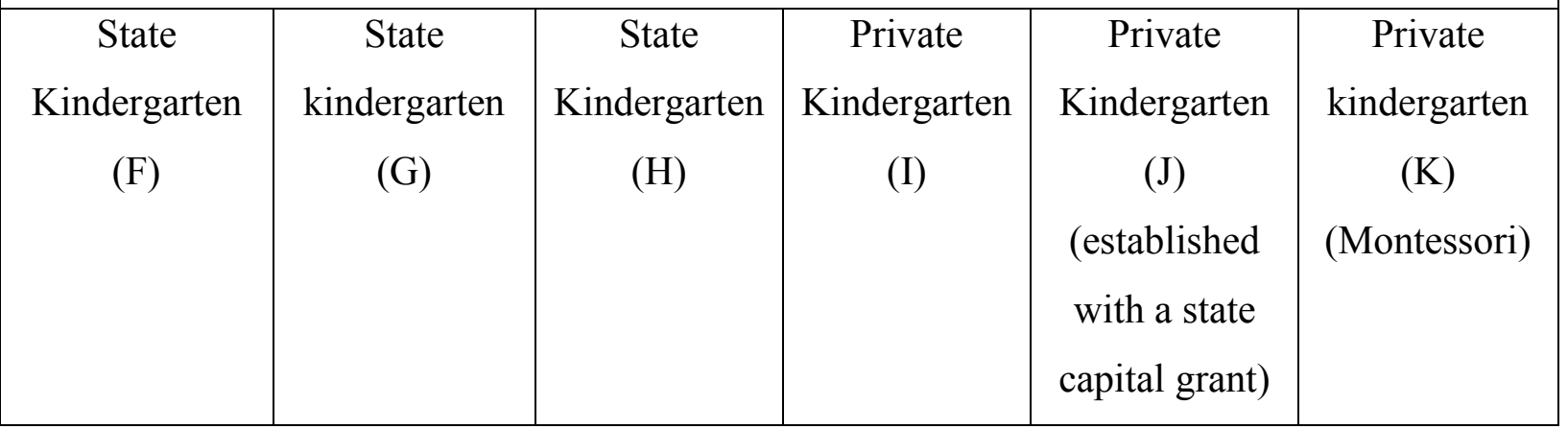

Ethical processes were overseen by Nazarbayev University. Photographs of the preschool environments were taken with the permission of staff to help detail and analyse observations 
from learning walks exploring the resources and methods employed in the settings (Hryniewicz 2016). Care was taken not to store or use images identifying children. The numbers of the kindergartens, the identities of respondents and the photographs, have not been used in reporting on the visits, and attribution of comments have been anonymised for ethical reasons (Harcourt, Perry \& Waller 2011). The aim of the data collection process was to assess the nature of the kindergarten learning environments and to ask staff about the influence of the national standards on their teaching, including how pre-service and in-service training supported the application of the standards to practice.

\section{Findings and Analysis}

\section{The relative stickiness of ideas in policy and practice}

The director for preschool education at the Ministry of Education(B) identified a vision for change that corresponded with the OECDs recommendations for a balance of child-led and adult-initiated pedagogies. "The priority for change is to move from a more school-like classroom environment to a more play based experience for children. Preschool should be a transformative space for children including outdoor play, and sport. Outdoor play should take place outside on daily basis and children should be taken out into the real world environment to learn. Lessons should not be holding children in the classroom. Good teachers should be caring and able to make the children laugh." (Interview B)

Interviews with two of those involved in a working party tasked by the Ministry of Education with developing a revised standards document to supersede the 2012 version, suggested that the group wanted the revised standards to reflect more strongly the idea that children should have more opportunities to choose and play (Interviews $\mathrm{C}$ and $\mathrm{J}$ ). They hoped that the next iteration of the standards would match what they observed to be Kazakh children's increased confidence and understanding. This they associated with children having greater access to ideas knowledge through the media revolution in the country and parenting styles that promote autonomy. The kindergarten staff interviewed in each setting also expressed a desire to follow children's interests and promote children's learning through play.

While the stated aims of the standards documentation, practitioners, policy makers and trainers suggested a commitment to emerging social changes in attitudes to childhood and child-focused 
pedagogy, the interviews and observations also suggested the stickiness of existing pedagogical practices. The participation of children in activities was evident in the classroom sessions observed, but with the exception of one of the preschools, the children were always observed participating in whole class activity in the indoor classroom environments: free play was observed in the kindergartens' outdoor environments. Each kindergarten director interviewed was very explicit that they followed the standards documents and the supporting curriculum as set out in policy and in the prescribed textbooks. The perceived need to follow a set subject curriculum meant that an adult-led curriculum accounted for much of the content of the children's day. English, Music, dance, sports in at least two of the settings were taught each in a different specialist room by a specialist teacher. In the subject sessions there was usually one adult teacher in charge of a group of 24 leading with another assistant supporting the activity (Interviews F,G,H,I, J and K).

A group of Kindergarten directors and trainers from the Astana city authority (Interview E) confirmed the continuing influence of class-based subject-focused lessons in practitioners' interpretations of the national standards:

Learning is mostly in classes with each centre following a set timetable programme for each subject as described by the books identified in the standards.

Section three of the 2012 standards set out the expectation that children would engage with the prescribed curriculum for 24 hours of teaching per week. The 2008 and 2001 versions of the preschool standards (still in force) defined the balance of subject hours for different age groups. The senior age group were recommended to receive 14.5 hours of identified subjects plus 1.5 hours for language development depending based around children interests and play.

The continuing identification of recommended maximum times for different subjects seems to sustain a subject-focussed lessons rather than facilitate a more integrated approach to learning. The language of the standards documents frequently emphasised the teacher delivering learning rather than children exploring learning. Interviews revealed that regular inspections of settings against the National Standards do promote that the idea of children being active participants, but also mean that kindergarten practitioners feel the need to demonstrate they are delivering the required hours of subject content (Interviews E,F,H I, and J). The Kindergarten headteachers in 
interviews $\mathrm{G}$ and $\mathrm{J}$ indicated alternative more flexible interpretations of an integrated play curriculum for parts of the kindergarten day but still acknowledged the pressure to demonstrate some specific content periods.

Gladwell's analysis of stickiness arguing for ideas to be expressed simply and explicitly is very helpful. One of the Kindergarten teachers summarised what she was doing as 'less teaching from the front': this might resonate clearly with a wide range of stakeholders.

Acknowledging the influence of colonial traditions of "teaching from the front" together with questioning the relevance and pragmatics of neo-colonial practices from other countries is an important base from which to formulate a locally relevant kindergarten offer. This would require further dialogues, where stakeholders could explore the continuing momentum of existing methods and the prevailing view of how much learning is to be experienced in a group led by a practitioner. This could help in developing distinct clear and less-conflicting messages to practitioners incorporated into the national standards, pre-service and in-service training. Local institutions could then develop pedagogy that makes sense in the context to the kindergarten environments and the communities they support.

\section{The circumstances of the context in which the idea is operating}

The literature review drew attention to the influence that 'place' can exert on the adoption of ideas (Gladwell 2001, Rogoff 2003, Pacini-Ketchabaw and Taylor 2015). The visits to the state and private kindergartens suggested many similarities between the layouts and practice environments that might help to support the persistence of adult-led pedagogy and resist the adoption of alternative practice.

The Kindergartens operated in two-storey buildings surrounded by sufficient land to offer plenty of outdoor play space. The buildings featured very similar layouts, with suites of rooms for different age groups and some subject-specific rooms. Each suite comprised a larger base room, with a connecting dormitory room containing sufficient beds for each child. Each kindergarten's day was from $8 \mathrm{am}$ to $6 \mathrm{pm}$, with a lunch break around $12.30 \mathrm{pm}$ followed by a sleep period of one to two hours. The fabric of buildings and layout of the rooms themselves potentially offer 
sufficient space for child-led activities to be possible. There is space for a variety of games and role-play areas to be offered simultaneously and the rearrangement of desks, chairs and floor surfaces would all permit more play-based activity. None of the rooms had direct access to outdoor play areas so children so the development of free-flow inside/outside activity was not possible without adaptations, but such a change could be accommodated but would be limited by the extremes of summer and winter temperatures.

One privately managed centre (F) demonstrated a marked contrast in the style of teaching and learning. The leader of this centre had studied at the Montessori Institute in Moscow. In the mornings, the desks were moved to open up more floor space and the children experienced an extended period of play-based activity where they were free to choose from a variety of painting, drawing, role-play and other structured educational toys in the setting. The leader explained that it had been quite a challenge to find the play equipment and it had been imported at a relatively high cost. The leader said that the children enjoyed the morning sessions and that in the afternoons they experienced the more traditional "teaching from the front". They had quite a few children transfer from other more traditional preschools who found it hard to choose for themselves at first. She believed that learning to manage their own activity and learning was a key benefit of this approach. This suggests that the wider social environment, at least in the Astana area, might also be supportive of a shift in the established dominant kindergarten pedagogy.

\section{The number, power and connectedness of the key individuals spreading an idea.}

The interviewees represent some of the key agents engaged with addressing the "structural hole" (Ball and Junnemann 2012) creating a new vision of child centred pedagogy. Six of those interviewed were involved in the development of a revised standards as a first step to making a revised vision of pedagogy more visible. One problem commonly identified in the interviews with both policy makers and practitioners in Astana was the limited experience of preschool leaders and trainers.

Following international trends for modernisation is a problem because there is very limited experience of these approaches in the country. (National training director) 
According to 2013 data, only $57 \%$ of preschool teachers had attended higher education a factor that may impede shared understandings of debates at a higher pedagogic level (Fimyar et al. 2014). The identification and development of preschool advocates from within Kazakhstan could be an important step in developing investment in a group of people with the skills to share a vision of practice.

Gladwell's analysis of the significance of the right people and social structures in supporting change highlights that it is not always the best practitioners or external experts who have the most influence, but rather those who are skilled at bringing people together, picking up, nurturing and sustaining contacts. Careful thought should be given to the selection of key trainers at a regional level and the potential of developing model kindergarten centres. Practice innovators need to have job descriptions, which allow them to visit and network within local regions. They may also need to develop additional skills for training such as communication skills in digital media and other languages to enhance their capacity to act as go-betweens linking ideas and practice.

To address Jonson's concerns about the parachuting in of pedagogical practices, the development of centres of good practice could be very helpful. Practice innovators based in model centres could support others from a position of informed authority about how their pedagogy came into existence and how it fits with children's and parents' expectations. Organisations such as the existing 'Orleu' in-service teacher training institute that supports professional development across Kazakhstan could provide such a network through investment in skilled "social connectors". The Director of the Orleu recognised her role in creating such a network based not just in a central team located but drawn from local networks connected to a variety of cultural contexts.

\section{Conclusion}

Post-colonial perspectives (Braidotti 2013) can be helpful in alerting us to the unconscious continuance of past ideologies into new practices because they illuminate how the modernist foundations of education continue to shape emerging policy and practice. Most practitioners, policy makers and parents have been shaped by a subject-based pedagogy with the potential to 
establish a value system that finds it challenging to adopt a more integrated or process orientated pedagogy. Thus, while there is little research evidence confirming that a preschool pedagogy echoing school subjects is an effective preparation for school (OECD 2012), it may still feel to many adults like the right thing to do.

The interviews with practitioners in Astana revealed a commitment to active learning and play but a strong pull towards the idea of a subject based curriculum. Recognising the strength of this underlying discourse is important because it suggests that any change will need to either challenge the validity of this discourse or show how revised practices compliment it. The subject-based nature of schooling that is embodied in the buildings and curriculum expectations frame the kindergarten day in the minds of practitioners, parents and children. The Astana case study suggests the power of the idea of modernity over education to organise, compartmentalise, institutionalise, order and control learning. Thus, the past continues to exert a powerful sway on what societies believe preschool should prepare children for. Recognising the strength of this underlying discourse is important because it suggests that any change will need to either challenge the validity of this discourse or show how revised practices compliment it. It may therefore be helpful to stop referring to 'traditional and modern approaches' in the debate about the place for play and child led learning in early education. Characterising change in this way is unhelpful because it puts individuals into a binary where they have to position themselves as one thing or another. Societies might be more comfortable with a blended spectrum of experiences of adult and child-led activities preparing children for school and life.

Gladwell's analysis of tipping points draws attention to the need to ground pedagogy in values that make sense and feel right to practitioners, parents, children and wider society. However, this may favour the deeply embedded sense of subject that many adults take away from their experience of education. To emphasise school readiness in policy documents may undermine more play-based, child-initiated pedagogy. While it is possible to argue for kindergarten to be a separate phase from education, it may be more helpful to argue for Kindergarten being a broader preparation for lifelong wellbeing. A tipping point towards more child-initiated practice might require people to be convinced that change with complement existing subject knowledge. A 
vision of upbringing more committed to ecological, health concerns and creativity is appeal to many.

The children in the Astana settings visited appeared to be comfortable, alert and eager to participate in the activities that comprised their day. They worked enthusiastically together in large groups, took turns, listened to each other's conversations. There were opportunities for them to engage with play resources between lessons and they were free to engage with outdoor play spaces at several points through the day. In these more playful spaces, staff engaged in informal conversations with the children and admired the children's play. This paper has tried to convey the enthusiasm of the practitioners, leaders, trainers and policy makers, for developing the opportunities for more child led activity, together with the desire within the system to reduce the dominance of whole class teaching. Policy makers and practitioners both made reference to a sense of changing expectations for children and childhood and this is perhaps an important starting to reflect on what a new nation aspires to for its children not just in schooling but for their lifelong wellbeing. Upbringing (Vospitaniye) was a term that kept coming up in the Astana interviews and which features in the title of the standards document the State Education Standards of Preschool Upbringing and Education. If school-based education is deeply rooted in 'modern' social structures, then the concept of 'upbringing' is perhaps more flexible, being associated not just with school but with wider social institutions such as the media as well as with home, family, friends and community. Upbringing is perhaps more open to suggesting a blending of traditional and modern influences it is suggestive of introducing children to more contemporary technologies and thinking but also to promoting a sense of place, community and belonging. It may, therefore be a helpful foundation from which to build towards a sustainable tipping point.

\section{Disclosure Statement}

No potential conflict of interest was reported by the authors

\section{Funding}


This work was supported by The Kazakhstan Government.

\section{Acknowledgements}

The authors would like to pay tribute to Daurenbek Kuleimenov who was tragically taken from us during the production of this article and who contributed so much in organising this project. We would also like to thank the participating Kindergartens, Rachel Holmes and Olga Mun for their valuable input.

\section{References}

Aitken, J. 2012. Kazakhstan Surprises and Stereotypes After 20 Years of Independence. London: Bloomsbury

BALL, S. (1990) Politics and Policy Making in Education London: Routledge

Ball, S.J. \& Junemann, C. 2012, Networks, new governance and education, Bristol: Policy Press.

Ball, S.J., Goodson, I. and Maguire, M. 2007, Education, globalisation, and new times, Routledge, London.

Braidotti, R. 2013. The Posthuman, Polity: Cambridge.

Bridges, D. and Sagintayeva A. 2014. Introduction chapter in Bridges, D. 2014. Educational Reform and Internationalisation: the Case of School Reform in Kazakhstan Cambridge: Cambridge University Press.

Bridges, D., Kurakbayev, K. and Kambatyrov, A. (2014) Lost - and Found- in Translation? Interpreting the process of the International and International Translation of educational Policy and practice in Kazakhstan. Bridges, D. 2014 Educational Reform and Internationalisation: the Case of School Reform in Kazakhstan Cambridge: Cambridge University Press.

Brummell, P. 2011, Kazakhstan $2^{\text {nd }}$ Edition Chalfont St Peter: Bradt.

Dalli, C., White, E.J., Rockel, J., Duhn, I., Buchanan, E., Davidson, S., Ganly, S., Kus, L. and Wang, B. 2011. Quality Early Childhood Education for Under-Two-Year-Olds: What Should it Look Like? A Literature Review, Ministry of Education, Wellington, 
www.educationcounts.govt.nz/publications/ECE/Quality_ECE_for_under-two-yearolds/965_QualityECE_Web-22032011.pdf (accessed 26.08.2015)

Elo, S., Kääriäinen, M., Kanste, O., Pölkki,T. Utriainen, K., and Kyngäs, H. (2014) Qualitative Content Analysis Sage Open 4, 1 p1-10

Fimyar, O., Yankavets, N., and Bridges, D. 2014. Educational reform in Kazakhstan: the contemporary policy agenda chapter in Bridges, D. 2014. Educational Reform and Internationalisation: the Case of School Reform in Kazakhstan Cambridge: Cambridge University Press.

Georgeson, J. and Payler, J. 2013, International perspectives on early childhood education and care. Maidenhead: Open University Press.

Giddens, A. 1990, The consequences of modernity, Polity Press in association with Blackwell, Cambridge

Gladwell, M. (2001) The Tipping Point London: Abacus.

Hamilton, L. and Corbett-Whittier, C. 2012, BERA/SAGE Research Methods in Education: Using Case Study in Education Research, London:Sage.

Harcourt, D., Perry, B. and Waller, T. 2011, Researching young children's perspectives: debating the ethics and dilemmas of educational research with children. London: Routledge.

Hryniewicz, L. (2016) An examination of the development and nature of professional identity in Five Early Years Professionals/ Early Years Teachers in England - a phenomenological study Thesis submitted for the Degree of Doctorate in Education Canterbury: Canterbury Christ Church University

Janz, B. 2012. Forget Deleuze in Burns, L. and Kaiser, B.M. 2012. Postcolonial literatures and Deleuze: colonial pasts, differential futures. Basingstoke: Palgrave Macmillan p21-36.

Johnson, R. 2000, "Colonialism and Cargo Cults in Early Childhood Education: Does Reggio Emilia Really Exist?", Contemporary Issues in Early Childhood, 1, 1, p. 61-78

King, K. 2011, Networked reenactments: stories transdisciplinary knowledges tell. Durham, N.C: Duke University Press. 
McLaughlin, C., McLellan, R., Fordham, M., Chander-Grevatt, A., and Daubney, A. (2014) The Role of the Teacher in Educational Reform in Kazakhstan: Teacher Enquiry as a Vehicle for Change in Bridges, D. (2014) Educational Reform and Internationalisation: the Case of School Reform in Kazakhstan Cambridge: Cambridge University Press.

Ministry for Education (MfE) (2002) National Standards for Preschools in Kazakhstan. Astana: Ministry for Education.

Ministry for Education(MfE) (2008) National Standards for Preschools in Kazakhstan. Astana: Ministry for Education.

Ministry for Education (MfE) (2012) National Standards for Preschools in Kazakhstan. Astana: Ministry for Education.

Moss, P., Dahlberg, G., Grieshaber, S., Mantovani, S., May, H., Pence, A., Rayna, S., Swadener, B.B. and Vandenbroeck, M. 2016, The Organisation for Economic Co-operation and Developments International Early Learning Study: Opening for debate and contestation, Contemporary Issues in Early Childhood, vol. 17, no. 3, pp. 343-351

Organisation for Economic Cooperation and Development OECD (2011) OECD 50th Anniversary Vision Statement www.oecd.org/mcm/48064973.pdf

Organisation for Economic Cooperation and Development OECD (2012) Starting Strong III www.oecd.org/edu/school/startingstrongiiiaqualitytoolboxforearlychildhoodeducationandcare.htm Organisation for Economic Cooperation and Development OECD (2015) Starting Strong IV www.keepeek.com/Digital-Asset-Management/oecd/education/starting-strongiv_9789264233515-en

Pacini-Ketchabaw, V. and Taylor, A. (2015) Unsettling the Colonial Places and Spaces of Early Childhood Education; New York: Routledge

Robson, C. and McCartan, K. (2016) Real world research, 4th Edition, Hoboken: Wiley. Rogoff, B. (2003), The cultural nature of human development Oxford: Oxford University Press 
Sahlberg, P. (2015) Finnish Lessons 2.0: What Can the World Learn from Educational Change in Finland?, Second Edition New York: Teachers College, Columbia University.

Schweinhart, L. J., Montie, J., Xiang, Z., Barnett, W. S., Belfield, C. R. \& Nores, M. (2005)

Finding of the Perry preschool programme thru to age 40. Ypsilanti, Mi: High/Scope Press.

Schweinhart, L.J. 2013, "Long-term follow-up of a preschool experiment", Journal of

Experimental Criminology, vol. 9, no. 4 pp. 389-409.

Shamshidinova, K., Ayubayeva, N., and Bridges, D. (2014) Implementing Radical Change:

Nazarbayev Intellectual Schools as Agents of Change chapter in Bridges, D. (2014) Educational

Reform and Internationalisation: the Case of School Reform in Kazakhstan Cambridge:

Cambridge University Press

Somdahl-Sands, K. and Finn, J.C. (2015) Media, performance, and pastpresents: authenticity in the digital age. GeoJournal 80: 811.

Sylva, K., Melhuish, E., Sammons, P., Siraj-Blatchford, I. and Taggart, B. (2010) Early childhood matters evidence from the effective pre-school and primary education project. London: Routledge.

Taguma, M., Litjens, I. and Makowiecki, K. (2012) Quality Matters in Early Childhood Education and Care: New Zealand 2012, Paris: OECD Publishing.

Tharp, R. \& Gallimore, R. (1988) Rousing minds to life. New York: Cambridge University Press

Wylie, C. and Thompson, J. (2003) The long-term contribution of early childhood education to children's performance- evidence from New Zealand. International Journal of Early Years Education, 11(1), 69- 78.

Yoshikawa, H. (2016) Improving the Quality of Early Childhood Education in the Context of the UN Sustainable Development Goals Key Note Address presented at The $26^{\text {th }}$ European Early Childhood Education Research Association Conference, Dublin, $1^{\text {st }}$ September 2016. 